Portland State University

PDXScholar

Engineering and Technology Management

Faculty Publications and Presentations

2019

\title{
Evaluation of the Cryptocurrency Adoption Decision Using Hierarchical Decision Modeling (HDM)
}

\author{
Saeed Alzahrani \\ Portland State University \\ Tugrul Daim \\ Portland State University, tugrul@etm.pdx.edu
}

Follow this and additional works at: https://pdxscholar.library.pdx.edu/etm_fac

Part of the E-Commerce Commons

Let us know how access to this document benefits you.

\section{Citation Details}

S. Alzahrani and T. U. Daim, "Evaluation of the Cryptocurrency Adoption Decision Using Hierarchical Decision Modeling (HDM)," 2019 Portland International Conference on Management of Engineering and Technology (PICMET), Portland, OR, USA, 2019, pp. 1-7.

This Article is brought to you for free and open access. It has been accepted for inclusion in Engineering and Technology Management Faculty Publications and Presentations by an authorized administrator of PDXScholar. Please contact us if we can make this document more accessible: pdxscholar@pdx.edu. 


\title{
Evaluation of the Cryptocurrency Adoption Decision Using Hierarchical Decision Modeling (HDM)
}

\author{
Saeed Alzahrani ${ }^{1,2}$, Tugrul U. Daim ${ }^{1}$ \\ ${ }^{1}$ Engineering and Technology Management Dept., Portland State University, Portland, OR 97201 USA \\ ${ }^{2}$ Management Information System Dept., King Saud University, Riyadh, Kingdom of Saudi Arabia
}

\begin{abstract}
In the recent years, there has been a massive attention toward cryptocurrency. The development of the blockchain technology has enabled the cryptocurrency to invade the financial industry by providing, to some extent, an alternative banking system with extra benefits such as lower cost of transaction, faster transaction processing, and higher level of privacy. Bitcoin is the first completely decentralized digital currency to exist in the cryptocurrency market. People have adopted cryptocurrency for several reasons. This adoption is a purchasing decision where the users make the adoption decision based on set of factors that matter to them. This paper aims at evaluating the factors impacting the cryptocurrency adoption decision. To do so, we have identified the factors that the users consider when making the purchasing decision based on a comprehensive review of recent literature and expert's inputs. The objectives of the paper are to: (1) identify the factors impacting the adoption decision, (2) and determine the ranking of these factors based on the quantification of users' judgments. This paper proposes a Hierarchical Decision Model (HDM) to understand the users' decision to adopt cryptocurrency. The model suggests four main perspectives that influence the adoption decision namely: economic, technical, social, and personal. Every perspective consists of set of related criteria. We then used the pairwise comparison method to assess the importance of the perspectives and criteria to the overall objective of the model. The findings of this study suggest that users evaluate and make their decision mostly from economic and social perspectives. The top criteria found to influence the cryptocurrency adoption decision are the investment opportunity, subjective norms, businesses acceptance, privacy, and global attention. This paper provides insights into the factors impacting the adoption decision and their importance level. It also helps the cryptocurrency developers to understand the consumers' adoption criteria to encourage cryptocurrency adoption.
\end{abstract}

\section{INTRODUCTION}

Cryptocurrency has emerged in the recent years to propose a new form of digital currency. Cryptocurrency provides the benefits of serving as a peer-to-peer medium of exchange and a store of asset [1]. The emergence of this innovative technology as financial solution has grasped serious attention of individuals and governments. The financial crisis occurred in 2008 has led the mass to question the reliability and loss trust of the existing financial systems and look for an alternative one like the digital banking systems [2]. Cryptocurrency uses cryptographic methods for the transmission of the digital information to ensure the validity of the transactions [3]. The goal of cryptocurrencies is to enable users to conduct businesses and payments without the need for a central authority.

There is a considerable market for cryptocurrency. The total market value is increasing as it started the year of 2017 with total market value of $\$ 18$ billion to reach, according to coinmarketcap.com, a market value of over $\$ 459$ billion on March 2018 [4]. Bitcoin is on the top of the list with a market capitalization of around $\$ 186 \mathrm{~B}$. The first cryptocurrency released is Bitcoin in 2009 by pseudonymous entity named Satoshi Nakamoto with the goal of providing a system that enables faster transfer of funds at lower transaction fee [5]. Bitcoin is a decentralized peer-to-peer system that aims at replacing the central authority with cryptographic proof. The number of altcoins in the market as of February 2018 reached 1,498 different altcoins. Even though the first cryptocurrency started in 2009 but the real start of the cryptocurrency market was in 2013 as it started to attract the public attention [6]. Cryptocurrency are not printed like the dollars or euros, they are instead mined by a network of users running computers using certain software programs to solve mathematical problems [7]. The goal of cryptocurrency is to offer a financial system that is not tied to a government as the existing financial system.

In the technology space, the cryptocurrency industry has reached a significant market capitalization that is equivalent to big technology companies. According to coinmarketcap.com, the market value of the cryptocurrency reached over than $\$ 459$ billion as of March 2018 with Bitcoin accounting for about the third [4]. On the other hand, Facebook, Inc has market capitalization of $\$ 592 \mathrm{~B}$, Intel Corporation has a market value of \$ 241B, and Cisco Systems, Inc. has \$200B market value [8].

Users can either directly buy, mine, exchange for good or services to acquire cryptocurrency coins. The users' decision to buy or mine is based on several factors. The decision to buy or mine altcoins is influenced by the ease of use or mine, anonymity, privacy, value, and the currency technology [9]. The increase in the price of Bitcoin from just few cents in 2009 to more than a thousand dollars led people to think of the new currency comers seriously [6]. This attention has attracted the development of other altcoins as well.

The public perceptions and interest toward cryptocurrency is changing and can be observed by three ways: the cryptocurrency market capitalization, the estimated number of users, and the daily transaction volume [3]. Cryptocurrency is trending in the recent years especially for the young generation. A survey of more than 2,000 U.S. adults shows 
that $48 \%$ of millennials believes that Bitcoin is an innovation in the financial technology and $27 \%$ prefer to invest $\$ 1 \mathrm{~K}$ in Bitcoin than in stocks [10]. Moreover, 27\% of millennials believe Bitcoin is more trustworthy than banks. The survey expressed the millennials generation positive perception toward cryptocurrency [10]. The technological advancement and people's openness towards cryptocurrency are positive indicators of the diffusion and acceptance of the cryptocurrency [11]. People are open to adopting innovative technologies especially younger generations which opens the door for cryptocurrency adoption.

There is a lack of enough information about the cryptocurrency users. Characteristics of existing users such as age, time of initial use, geographic location, mining status, engaging online discourse, and political orientation can tell a lot about cryptocurrency community such as the attraction toward cryptocurrency, wealth, and optimism about its future [1]. Cryptocurrency users' demographic and economic characteristics, most likely, include a younger, non-white male with lower education, and has responsibility for household shopping [12]. It is important to understand the users' intentions to adopt cryptocurrency.

With this wave of cryptocurrency development and wild attention, it is important to understand the consumer's attitude toward the adoption of the cryptocurrency and the factors influencing their decision. Thus, the aim of the paper is to use a multi-perspective analysis approach to examine the factors influencing the user's cryptocurrency adoption decision.

\section{LITERATURE REVIEW}

\section{A. Cryptocurrency Adoption studies}

Even though, the research on the adoption and acceptance of cryptocurrency is scarce, there have been attempts to utilize the existing technology adoption and acceptance theories and models to investigate the users' intention to adopt cryptocurrency. An exploratory interview with cryptocurrency users indicates the usability, usefulness, and subjective norms as important factors for the future of the cryptocurrency [13]. One of the early adopters of the cryptocurrency as payment system is a drug marketplace called "Silk Road" [14]. The users of the website showed an interest in using the site to buy drugs for several reasons such as curiosity, concerns for personal safety, variety of products, anonymous transactioning, and ease of product delivery [14]. The website opened a door for the legality issues of using cryptocurrency to conduct illegal activities.

Researchers also have used theories such as Diffusion of Innovation Theory [15], Technology Acceptance Model [16], and Unified Theory of Acceptance and Use of Technology (UTAUT) [17] to understand different aspects of the cryptocurrency adoption. Presthus and O'Malley [18] investigated users' motivations and barriers of cryptocurrency adoption by applying the Rogers' Diffusion of Innovation theory. The finding suggests that technological curiosity is main motivator of the Bitcoin adoption. The study as well identified the value and security issues as the main concerns from non-user's perspective. Silinskyte [17] used the Unified
Theory of Acceptance and Use of Technology (UTAUT) model developed by Venkatesh et al. [19] to understand the user's usage behavior toward Bitcoin. The finding indicated that performance expectancy, effort expectancy, facilitating conditions and behavioral intention significantly influence the usage of Bitcoin. Another study used UTAUT model to study the Acceptance of Electronic Monetary Exchanges, Bitcoin, by Information Security Professionals [20]. The findings indicate that the factors influencing the acceptance intention to use Bitcoin include performance expectancy and effort expectancy. Additionally, facilitating conditions and behavioral intention significantly influence the actual usage of Bitcoin. However, the results do not support the original UTAUT model and a modification of the model is required for the case of Bitcoin. Folkinshteyn and Lennon [21] used the modified TAM developed by Pavlou [22] to analyze Bitcoin as a currency and the blockchain as a financial technology from the user's and developer's perspectives. They used the modified TAM to assess the perceived ease of use, perceived usefulness, and perceived risk, trust factors from the user's perspective toward Bitcoin. Perceived risks include factors such as security risk, user error, loss of privacy, and thirdparty service failure. Perceived ease of use construct includes fast transfer, free participation, and simple interface. Lastly, Perceived usefulness includes full control over own money, low cost of transfer, disintermediation, transaction security, and international scope. The nature and distinctive characteristics of cryptocurrency poses a challenging task to develop models that provide better understanding of the cryptocurrency adoption.

\section{B. Adoption Motivations}

Various motivations have been noted to attract consumers to adopt cryptocurrency. An interview with Bitcoin users identified the cryptocurrency expected role in a monetary revolution, users' increased empowerment and control over their money, and the perception of the value of Bitcoin currency as three major adoption motivations [23]. Another interview with cryptocurrency users in Malaysia reported the utilization of the cryptocurrency as a store of value for their wealth as main motivation of adoption [24]. Other users consider the high level of privacy and ability to have an alternative payment system as a reason to adopt cryptocurrency [25]. Due to the high level of privacy and anonymity cryptocurrency provides, some illegal activities such as money laundering drive the motivation toward the adoption [26]. A study conducted to examine the adoption of cryptocurrency motivations and what could facilitate the adoption revealed interesting findings [18]. Technological curiosity and investments opportunity are key drivers of the cryptocurrency adoption. Factors such as stability, security, acceptance as payment method and currency, usefulness, ease of use, clear laws and regulations, and accessibility would motivate and foster the adoption as well [18]. Bohr and Bashir studied the Bitcoin community and reported three main motivation of adoption: anonymity, freedom, and lack of trust in the banking system [1]. Alzahrani and Daim studied the cryptocurrency adoption decision and identified various 
technical, economic, social, and personal factors that influence the adoption decision [27]. Users indicate different interest in their adoption of the cryptocurrency.

\section{METHODOLOGY}

The number of studies discussing the cryptocurrency adoption factors is low and there is a lack of publications looking into the cryptocurrency adoption from multidimensional view. We used the Hierarchical Decision Model (HDM) to address the multi-dimensional assessment of the adoption decision.

Multi-criteria decision analyses approach is followed in this study. Hierarchical Decision Model (HDM) assists the decision maker by breaking down the decision problem into objective, perspectives, and criteria. Perspectives and criteria are evaluated and ranked in order to understand their relative importance in the adoption decision. The methodology to be followed in this paper as the following [28]: determine the essential elements of the HDM: objective, perspective and criteria for the assessment of the cryptocurrency adoption decision, create the pairwise comparisons (PCM) survey, distribute it among the cryptocurrency users to capture their opinions in a quantifiable way, use the PCM software [29] to determine the perspectives and criteria weights, determine their relative importance and impact in the adoption decision, and finally provide suggestions and recommendations based on the assessment of the factors driving the cryptocurrency adoption decision.

There have been many studies that have used HDM to evaluate the factors influencing the consumers' adoption decision of certain technologies from multi-dimensional view. Van Blommestein and Daim, studied the selection of an energy efficient device by examining the consumers purchasing decision in South Africa [28]. Alzahrani et al. assessed the factors influencing the users' selection of the best Carsharing alternative in Portland [30]. Shaygan et al., used HDM to evaluate the adoption criteria of the activity tracking wristbands for university students [31]. HDM has proved its effectiveness in examining and evaluating the customers' adoption decision of various technologies.

\section{A. GAPs and Research Objective}

There have been many researches investigating cryptocurrency especially Bitcoin. However, most of them touch upon only the technical aspects of cryptocurrency. There have been lack of enough research and knowledge about the user's adoption of cryptocurrency and there is a need for research on user's intentions toward the adoption of such new phenomena [1] [3]. Thus, the aim of the paper is to use a multi-perspective analysis approach to examine the factors impacting the user's cryptocurrency adoption decision.

\section{B. Hierarchical Decision Model (HDM)}

The perspectives and criteria were identified based on the previous literature review and discussion with cryptocurrency users. We determined the factors affecting the adoption decision. We have identified many factors, but we only focused on the most common and influential ones. We classified and grouped them into four main perspectives based on the synergy between these factors. The perspectives have strong impact on the adoption decision with varying extents determined by their belonging factors.

The perspectives identified for the HDM model were Technical, Economic, Social, and Personal. The description of each of the criteria within each perspective are described below.

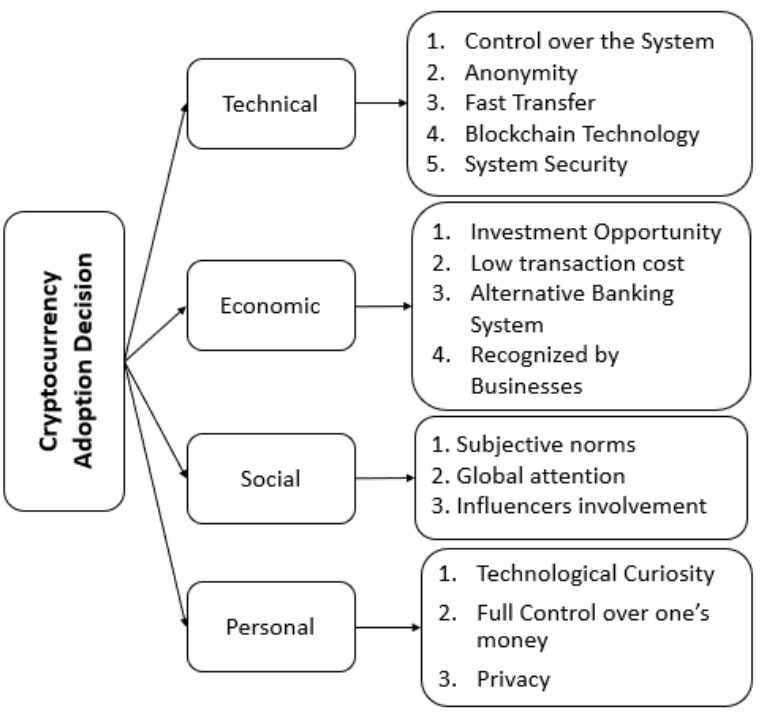

Fig. 1. HDM

\section{Perspectives and Criteria:}

\section{Technical:}

- Control over the System [3] [32] - this represent the existence of a central authority or intermediary in the network. Cryptocurrency may operate in either a peerto-peer decentralized system relying in the network of users such as Bitcoin or in a centralized system with central authority like Ripple.

- Anonymity [10] [12][24][33] - the level of anonymity cryptocurrency provides to its users. Cryptocurrency has very high level of anonymity. It is pseudoanonymity where the identities of the users are hidden with a private key and the only way for the lawmakers to intercept is in the original bank exchange of other currencies into the altcoins.

- Fast transfer [19] [32] - this represent the time it takes to send or receive funds or conduct a transaction. The transfer of altcoin from one wallet to another seems to nearly be instantaneous to a few minutes. The transfer is available $24 / 7$ and is not subject to operation hours or downtime as in the traditional banking system.

- Blockchain Technology [34] [35] - this represent the utilization of the blockchain technology to serve as a financial software platform. Blockchain "is an open, distributed ledger that can record transactions between two parties efficiently and in a verifiable and prominent way". It provides several benefits for the users such as reducing the transactions costs and eliminating the intermediaries. 
- System Security [19] [33] [36] [37] - this indicates the level of security the system has and how easy it can be to hack it. Cryptocurrency has very high level of system security where it is very hard to take it down. The only way a decentralized system can be hacked into is for the hacker to take control of more than $50 \%$ of the coins on the network which is almost impossible. However, the security of the users' wealth falls in their hands as it can be very easy to hack into the users' personal computer and steal their coins or wallet numbers.

Economic:

- Investment opportunity [38] [39] - Cryptocurrency may serve as an investment opportunity as the general trend of the cryptocurrency prices over the past years is increasing. The cryptocurrency market now includes hundreds of altcoins that are priced under a dollar and sometimes even less than a cent. Bitcoin at one point was traded at less than a dollar where it reached more than $\$ 18,000$ in the end of 2017.

- Low transaction cost [19] [32] [40] - the transaction fee is very low in comparison to the traditional banks or intermediaries. This will help especially for the international remittance market where the transaction cost or transfer fee is calculated at a high percentage of the transaction value.

- Alternative Banking System [16] [19] [22] [36] [41] [42] [43] - cryptocurrency can offer an alternative banking system for many reasons. Many people have lost trust in the existing financial system. Cryptocurrency can be used as a store of value or assets as well as a currency. People in countries with fluctuated exchange rate such as Argentina and Nicaragua or with unstable political situation can use cryptocurrency to store the value of their wealth. It, as well, can be a viable solution for populations living in underdeveloped countries and struggling economies. It helps in providing access to financial services and banking system. According to reports, there are around two billion people have none to limited access to formal financial services.

- Recognized by Businesses [16][12][36][44][45] - this represents the level of businesses acceptance of the cryptocurrency as a payment method. Many businesses have started accepting different altcoins as a payment method as well as user's interests in using Bitcoin to pay for goods and services. leading companies now are accepting cryptocurrency as a payment method including: Microsoft, Tesla, Virgin Galactic, Reddit, CheapAir.com, and Expedia.

\section{Social Factors:}

- Subjective norms [11][15][18][46] - it is the degree to which an individual perceives that important others believe he/she should adopt and use cryptocurrency. The influence of family and friends is important determinant of the cryptocurrency adoption.

- Global attention [4][36][47][48] - the recent world attention toward the cryptocurrency has increased dramatically especially when the prices skyrocketed in end of 2017 and beginning of 2018. The regulatory efforts from governments around the world have brought a massive attention and interest toward cryptocurrency. There are no formal laws or regulations worldwide. Also, the global attention measured through the search volume has proved its popularity.

- Influencers involvement [49][50][51] - recognizable business people, technology guru, influencers, and celebrities has announced either their interest in involving in cryptocurrency or already have involved.

\section{Personal:}

- Technological Curiosity [16][52][53]- cryptocurrency is a new innovation that attracts the attention of early adopters with high interest in adopting new technologies. Curiosity toward this new concept of money plays a role in the adoption of cryptocurrency.

- The level of Control Over one's Money [19][33] cryptocurrency gives the users full control over their money as it allows users to send or receive whatever amount of money to anywhere in the world and to whom they wish to.

- Privacy: [19] [23] [33] [52] - cryptocurrency provides very higher level of privacy. No one can know how much coins one's own or where they spend it at or for what purpose. The elimination of intermediaries improves the privacy level desired.

\section{Experts}

The experts for the model are the cryptocurrency users, the people making the decision to adopt cryptocurrency. The experts were identified are cryptocurrency adopters at different adoption levels. The HDM criteria were identified based on the literature review and the experts' opinion. The pairwise comparison survey was sent to a total of 12 experts and all of experts' responses were completed and collected. The respondent's ages range from the late-twenties to early thirties and are either graduate students or professionals in their respective fields.

\section{E. Pairwise Comparison}

The survey of the pairwise comparisons was sent through the Pairwise Comparison Method (PCM) software [29] in order to obtain and calculate the weights for the perspectives and criteria.

\section{RESULTS ANALYSIS AND DISCUSSION}

We used HDM to structure the adoption decision into objective, perspective, and criteria. The HDM helps to understand the factors that influence users' decision to adopt cryptocurrency. This section presents the result analysis and discussion:

\section{A. Inconsistency and Disagreement}

The level of inconsistency for the expert's in this model is at the acceptable level in which it is below 0.10 and it can be stated that the expert's judgments and inputs were consistent. The inconsistency level above 0.10 occurs when the 
comparisons of the preferences are not aligned. Inconsistency level measures the validation of the results. Furthermore, the disagreement level among the experts is at the acceptable range as it is below the 0.10 threshold which was 0.03 in this model.

\section{B. Perspectives Ranking}

Among the four perspectives proposed in this study, the economic and social perspectives were shown to have the highest weights while the technical and personal perspectives have the lowest weights. Fig. 2 shows the perspectives weights:

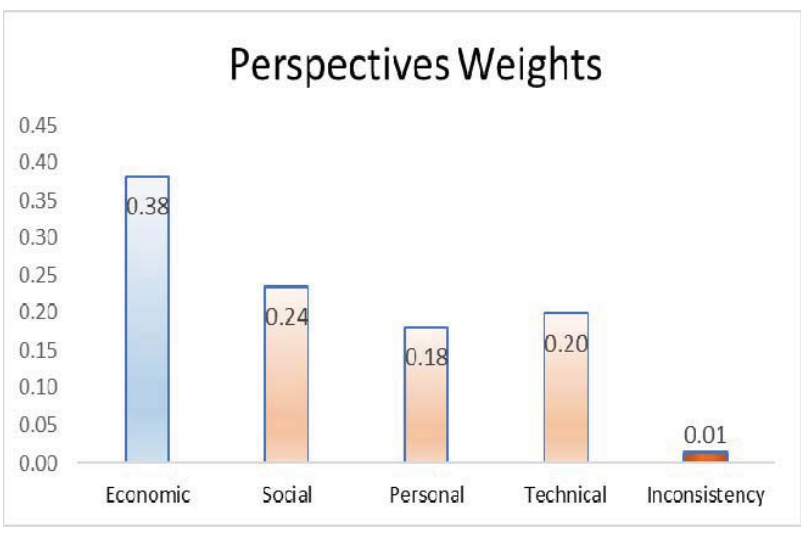

Fig. 2. Perspective Weights

\section{Criteria Ranking}

The analysis of the criteria in each of their respective perspective shows that people look for the cryptocurrency as an investment opportunity from the economic perspective, they emphasis the system security from the technical perspective, their decision is influenced by their family and friends from social perspective, and the privacy still matters from a personal perspective. The following table shows the criteria weights:

\begin{tabular}{|c|c|c|}
\multicolumn{2}{c}{ TABLE I. } & \multicolumn{2}{c}{ CRITERIA RESUlTS } \\
\hline Perspective & Criteria & Weight \\
\hline \multirow{4}{*}{$\begin{array}{c}\text { Economic } \\
(0.38)\end{array}$} & Investment Opportunity & 0.18 \\
\cline { 2 - 3 } & Low Transaction Cost & 0.06 \\
\cline { 2 - 3 } & $\begin{array}{c}\text { Alternative Banking } \\
\text { System }\end{array}$ & 0.05 \\
\cline { 2 - 3 } & Recognized by Businesses & 0.09 \\
\hline \multirow{3}{*}{$\begin{array}{c}\text { Technical } \\
(0.20)\end{array}$} & Control over the System & 0.04 \\
\cline { 2 - 3 } & Anonymity & 0.03 \\
\cline { 2 - 3 } & Fast Transfer & 0.04 \\
\cline { 2 - 3 } & Blockchain Technology & 0.03 \\
\hline \multirow{2}{*}{$\begin{array}{c}\text { Social } \\
(0.24)\end{array}$} & Sys Security & 0.06 \\
\cline { 2 - 3 } & Subjective Norms & 0.11 \\
\cline { 2 - 3 } & Influencers' Involvement & 0.07 \\
\hline \multirow{3}{*}{$\begin{array}{c}\text { Personal } \\
(0.19)\end{array}$} & Technological Curiosity & 0.04 \\
\cline { 2 - 3 } & Full Control Over one's & 0.06 \\
\cline { 2 - 3 } & Money & 0.09 \\
\hline
\end{tabular}

The table shows the universal weights of every criterion to the objective as well. The weight of each criterion represents its impact to the overall adoption decision. It shows that the "investment opportunity" factor was the most important factor to users when making the adoption decision followed by "Subjective norms" and then the "businesses acceptance" and "Privacy" factors.

\section{Top Factors for Consumers}

Tables 1 shows the top factors that matter to users when making the decision to adopt in cryptocurrency:

TABLE II. TOP FACTORS IN THE ADOPTION DECISION

\begin{tabular}{|c|c|c|}
\hline Top Factors & Perspective & Weight \\
\hline Investment opportunity & Economic & 0.18 \\
\hline Subjective norms & Social & 0.11 \\
\hline Recognized by businesses & Economic & 0.09 \\
\hline Privacy & Personal & 0.09 \\
\hline Global Attention & Social & 0.07 \\
\hline
\end{tabular}

The above table shows that most of the top factors belong to the economic and social perspectives. It can be said that people mostly make their decision from an economic perspective and influence by social factors.

\section{E. Result discussion}

The above analysis shows the key factors influencing the cryptocurrency adoption decision. The top factor users make their decision upon is the "investment opportunity" factor which align with a previous study that suggests people adopt cryptocurrency to make a profit and consider it as an investment vehicle [16]. "Subjective norms" is a core construct in many of the technology acceptance models which is shown to be a significant adoption driver in this study. Users are willing to adopt cryptocurrency if their peers adopt them. Also, users want to use altcoins as payment system to pay for products and services as they have ranked the businesses acceptance of altcoin as payment system as important factors [16] [23]. Many well-known companies as well as local businesses have started accepting cryptocurrency as payment method, which have fostered its adoption. Businesses accept cryptocurrency to lower the transaction cost as well as offering their customers with another payment method. One study on Bitcoin users have shown that $33.3 \%$ of a 990 sample size used Bitcoin to pay for virtual goods and $27.5 \%$ for online shopping [33]. Due to the high level of privacy cryptocurrency offers to its users, it is ranked one of the top factors to users [23] [24]. The massive attention toward cryptocurrency in the recent years has resulted in an increase in the demand for the altcoins. These factors reveal that people would like to treat cryptocurrency as an investment opportunity as well as a currency. Moreover, regular consumers are not concerned with the technical aspects of the cryptocurrency despite the main distinguisher of the cryptocurrency is the technological innovation and uniqueness. The collection of the previous factors has proved their influence in the cryptocurrency adoption decision.

\section{FUTURE DIRECTIONS}

The decision model introduced in this paper could be extended in multiple directions for future research. A possible 
way is to add the top altcoins in the market to assess them based on the factors identified in this model and try to find the altcoin that best meets the users' criteria. The number of experts can be increased to provide higher level of accuracy to the study. The number of factors considered in this study could be expended to include more factors that are perceived to influence the users' decision such as the role of the team behind each cryptocurrency option available in the market, the supply limit in certain cryptocurrency as an important value determinant, and the regulation role in the cryptocurrency market.

\section{CONCLUSION}

The goal of this model is to understand users' decision to adopt cryptocurrency from multiple perspectives. A Hierarchical Decision Model (HDM) was developed to understand this adoption decision. The experts' judgments have been captured in order to identify the top factors. The study suggests that investment opportunity, subjective norms, businesses acceptance, privacy, and global attention factors are the top factors that are perceived to influence the users' cryptocurrency adoption decision. Although, this model tries to include the factors that impact the adoption decision, other factors can be added as the user's needs changes over time. Adoption decision drawbacks could be added to the model to examine if the adoption decision would be influenced by the challenges and shortcomings of the cryptocurrency. Regulation uncertainty could be a significant factor that hinders the adoption of the cryptocurrency. This model can help the regulators and the existing financial systems to pursue more efforts in meeting the consumer needs and better understand their adoption of an alternative currency.

\section{REFERENCES}

[1] J. Bohr and M. Bashir, "Who Uses Bitcoin? An exploration of the Bitcoin community," in 2014 Twelfth Annual International Conference on Privacy, Security and Trust, 2014, pp. 94-101.

[2] N. N. Y. Vo and G. Xu, "The volatility of Bitcoin returns and its correlation to financial markets," 2017, pp. 1-6.

[3] R. Farell, "An analysis of the cryptocurrency industry," Wharton ResearchScholars Journal, p. 130, 2015.

[4] A. Paul, "It's 1994 In Cryptocurrency," Forbes, 27-Nov-2017. [Online]. Available: https://www.forbes.com/sites/apaul/2017/11/27/its-1994-incryptocurrency/\#6c82bb9db28a. [Accessed: 01-Mar-2018].

[5] S. Nakamoto, "Bitcoin: A Peer-to-Peer Electronic Cash System," 2008.

[6] F. Galetic, I. Potocki, and B. Jakovic, "Virtual Currencies as Payment Method of Contemporary Economy," in International OFEL Conference on Governance, Management and Entrepreneurship, 2015, pp. 1109-1127.

[7] T. Gibbs and S. Yordchim, "Thai Perception on Litecoin Value," World Academy of Science, Engineering and Technology, International Journal of Social, Behavioral, Educational, Economic, Business and Industrial Engineering, vol. 8, no. 8, pp. 2626-2628, 2014.

[8] "Stock Screener - Yahoo Finance," Yahoo! Finance. [Online]. Available: https://finance.yahoo.com/screener/predefined/technology/. [Accessed: 09-Jul-2018].

[9] A. A. Shehhi, M. Oudah, and Z. Aung, "Investigating factors behind choosing a cryptocurrency," in 2014 IEEE International Conference on Industrial Engineering and Engineering Management, 2014, pp. 1443-1447.

[10] "Blockchain Capital - Bitcoin Survey 2017," Blockchain Capital. .
[11] S. Mirzayi and M. Mehrzad, "Bitcoin, an SWOT analysis," 2017, pp. 205-210.

[12] S. Schuh and O. Shy, "U.S. Consumers' Adoption and Use of Bitcoin and other Virtual Currencies," presented at the Retail payments: mapping out the road ahead, 2016.

[13] A. W. Baur, J. Bühler, M. Bick, and C. S. Bonorden, "Cryptocurrencies as a Disruption? Empirical Findings on User Adoption and Future Potential of Bitcoin and Co," in Open and Big Data Management and Innovation, 2015, pp. 63-80.

[14] M. C. Van Hout and T. Bingham, "Surfing the Silk Road': a study of users' experiences," Int. J. Drug Policy, vol. 24, no. 6, pp. 524-529, Nov. 2013.

[15] E. M. Rogers, Diffusion of innovations, 3rd ed. New York : London: Free Press; Collier Macmillan, 1983.

[16] F. D. Davis, "Perceived Usefulness, Perceived Ease of Use, and User Acceptance of Information Technology," MIS Quarterly, vol. 13, no. 3, pp. 319-340, 1989.

[17] J. Silinskyte, "Understanding Bitcoin adoption: Unified Theory of Acceptance and Use of Technology (UTAUT) application," Master Thesis, pp. 1-56, 2014.

[18] W. Presthus and N. O. O'Malley, "Motivations and Barriers for EndUser Adoption of Bitcoin as Digital Currency," Procedia Computer Science, vol. 121, pp. 89-97, Jan. 2017.

[19] V. Venkatesh, M. G. Morris, G. B. Davis, and F. D. Davis, "User Acceptance of Information Technology: Toward a Unified View," MIS Quarterly, vol. 27, no. 3, pp. 425-478, 2003.

[20] M. Hutchison, "Acceptance of Electronic Monetary Exchanges, Specifically Bitcoin, by Information Security Professionals: A Quantitative Study Using the Unified Theory of Acceptance and Use of Technology (UTAUT) Model," D.C.S., Colorado Technical University, United States -- Colorado, 2017.

[21] D. Folkinshteyn and M. Lennon, "Braving Bitcoin: A technology acceptance model (TAM) analysis," Journal of Information Technology Case and Application Research, vol. 18, no. 4, pp. 220249, Oct. 2016.

[22] P. A. Pavlou, "Consumer acceptance of electronic commerce: Integrating trust and risk with the technology acceptance model," International journal of electronic commerce, vol. 7, no. 3, pp. 101134, 2003

[23] I. E. Khairuddin, C. Sas, S. Clinch, and N. Davies, "Exploring Motivations for Bitcoin Technology Usage," in Proceedings of the 2016 CHI Conference Extended Abstracts on Human Factors in Computing Systems, New York, NY, USA, 2016, pp. 2872-2878.

[24] C. Sas and I. E. Khairuddin, "Design for Trust: An Exploration of the Challenges and Opportunities of Bitcoin Users," in Proceedings of the 2017 CHI Conference on Human Factors in Computing Systems, New York, NY, USA, 2017, pp. 6499-6510.

[25] B. Maurer, T. C. Nelms, and L. Swartz, "When perhaps the real problem is money itself!': the practical materiality of Bitcoin," Social Semiotics, vol. 23, no. 2, pp. 261-277, Apr. 2013.

[26] H. Karlstrøm, "Do libertarians dream of electric coins? The material embeddedness of Bitcoin," Distinktion: Scandinavian Journal of Social Theory, vol. 15, no. 1, pp. 23-36, 2014.

[27] S. Alzahrani and T. U. Daim, "Analysis of the Cryptocurrency Adoption Decision: Literature Review," in 2019 Portland International Conference on Management of Engineering and Technology (PICMET), 2019, p. 11.

[28] K. C. van Blommestein and T. U. Daim, "Residential energy efficient device adoption in South Africa," Sustainable Energy Technologies and Assessments, vol. 1, pp. 13-27, Mar. 2013.

[29] B. Bailey, software product for pairwise comparison method of judgment quantification - user manual. 1990.

[30] S. Alzahrani, A. Alzahrani, X. Dai, W.-C. Hsu, and R. Tiwari, "An Assessment of the Factors Influencing the Selection of the Best Carsharing Alternative in Portland Area Using Hierarchical Decision Modeling (HDM)," in 2019 Portland International Conference on Management of Engineering and Technology (PICMET), 2019, p. 7.

[31] A. Shaygan, D. O. Gungor, H. Kutgun, and A. Daneshi, "Adoption Criteria Evaluation of Activity Tracking Wristbands for University Students," in 2017 Portland International Conference on Management of Engineering and Technology (PICMET), 2017, pp. 17. 
[32] D. L. K. Chuen, L. Guo, and Y. Wang, "Cryptocurrency: A New Investment Opportunity?," The Journal of Alternative Investments, vol. 20, no. 3, pp. 16-40, Dec. 2017.

[33] K. Krombholz, A. Judmayer, M. Gusenbauer, and E. Weippl, "The other side of the coin: User experiences with bitcoin security and privacy," in International Conference on Financial Cryptography and Data Security, 2016, pp. 555-580.

[34] M. Iansiti and K. R. Lakhani, "The truth about blockchain: It will take years to transform business, but the journey begins now," Harvard Business Review, 01-Jan-2017. [Online]. Available: https://hbr.org/2017/01/the-truth-about-blockchain. [Accessed: 04May-2018].

[35] C. Stamford, “Gartner's 2016 Hype Cycle for Emerging Technologies Identifies Three Key Trends That Organizations Must Track to Gain Competitive Advantage," Gartner, 16-Aug-2016. [Online]. Available: https://www.gartner.com/newsroom/id/3412017. [Accessed: 04-May2018].

[36] J. K. Darlington III, “The Future of Bitcoin: Mapping the Global Adoption of World's Largest Cryptocurrency Through Benefit Analysis," 2014

[37] T. Samson, "Malware infects 30 percent of computers in U.S.," InfoWorld, 08-Aug-2012. [Online]. Available: https://www.infoworld.com/article/2618043/cyber-crime/malwareinfects-30-percent-of-computers-in-u-s-.html. [Accessed: 04-May$2018]$.

[38] F. Glaser, K. Zimmermann, M. Haferkorn, M. C. Weber, and M. Siering, "Bitcoin - Asset or Currency? Revealing Users' Hidden Intentions," Social Science Research Network, Rochester, NY, SSRN Scholarly Paper ID 2425247, Apr. 2014.

[39] D. Yermack, "Chapter 2 - Is Bitcoin a Real Currency? An Economic Appraisal," in Handbook of Digital Currency, D. L. K. Chuen, Ed. San Diego: Academic Press, 2015, pp. 31-43.

[40] T. Kim, "On the transaction cost of Bitcoin," Finance Research Letters, vol. 23, pp. 300-305, Nov. 2017.

[41] G. J. Larios-Hernández, "Blockchain entrepreneurship opportunity in the practices of the unbanked," Business Horizons, vol. 60, no. 6, pp. 865-874, Nov. 2017.

[42] J. Southurst, "ZipZap CEO: Argentina's Volatility Makes Bitcoin Look Stable," CoinDesk, 01-Apr-2014. [Online]. Available: https://www.coindesk.com/zipzap-ceo-argentinas-volatility-makesbitcoin-look-stable/. [Accessed: 04-Apr-2018].

[43] H.-K. Lu, L. Yang, P.-C. Lin, T.-H. Yang, and A. N. Chen, “A Study on Adoption of Bitcoin in Taiwan: Using Big Data Analysis of Social Media," in Proceedings of the 3rd International Conference on Communication and Information Processing, New York, NY, USA, 2017, pp. 32-38.

[44] M. Nishanian, "8 surprising places where you can pay with bitcoin," $\begin{array}{lll}\text { Business Insider. } \quad \text { [Online]. Available: } & \end{array}$ http://www.businessinsider.com/bitcoin-price-8-surprising-placeswhere-you-can-use-2017-10. [Accessed: 10-Apr-2018].

[45] M. Polasik, A. I. Piotrowska, T. P. Wisniewski, R. Kotkowski, and G. Lightfoot, "Price Fluctuations and the Use of Bitcoin: An Empirical Inquiry," International Journal of Electronic Commerce, vol. 20, no. 1, pp. 9-49, Sep. 2015.

[46] M. Fishbein and I. Ajzen, Belief, attitude, intention, and behavior: an introduction to theory and research. Reading, Mass: Addison-Wesley Pub. Co, 1975.

[47] D. G. Hileman and M. Rauchs, "Global Cryptocurrency Benchmarking Study," Cambridge Centre for Alternative Finance, Apr. 2017.

[48] D. Riley, "Global attention on cryptocurrencies intensifies as Congress considers new rules," SiliconANGLE, 19-Feb-2018.

[49] C. Clifford, "Mark Cuban: NBA's Dallas Mavericks will accept bitcoin next season," CNBC, 17-Jan-2018. [Online]. Available: https://www.cnbc.com/2018/01/17/mark-cuban-nbas-dallas-

mavericks-will-accept-bitcoin-next-season.html. [Accessed: 23-Apr2018]

[50] M. Rosulek, "14 Bitcoin quotes by famous people," Medium, 24-Aug2017 .

[51] E. Martin, "Celebrities who have endorsed or invested in cryptocurrency," 20-Dec-2017. [Online]. Available: https://www.cnbc.com/2017/12/20/celebrities-who-have-endorsed-orinvested-in-cryptocurrency.html. [Accessed: 23-Apr-2018].

[52] J. Bohannon, The bitcoin busts. American Association for the Advancement of Science, 2016

[53] K. Dokic, M. Radman-Funarić, and K. P. Galić, "The Relationship between the Cryptocurrency Value (Bitcoin) and Interest for it in the Region," in ENTRENOVA '15-ENTerprise REsearch InNOVAtion Conference, 2015. 